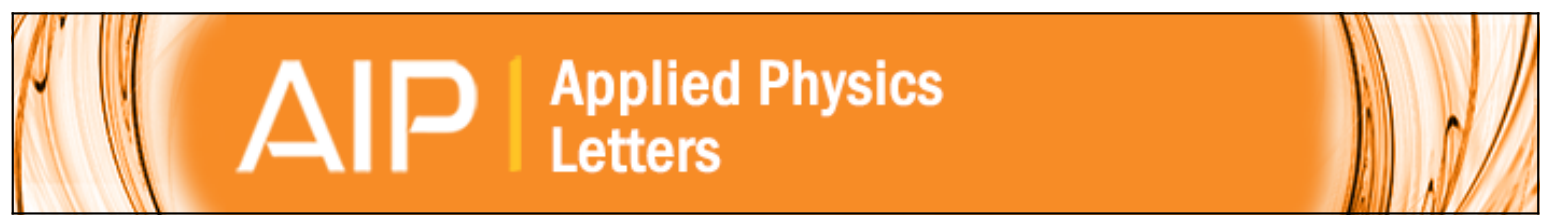

\title{
Highly conductive ZnO grown by pulsed laser deposition in pure $\mathrm{Ar}$
}

Robin C. Scott, Kevin D. Leedy, Burhan Bayraktaroglu, David C. Look, and Yong-Hang Zhang

Citation: Applied Physics Letters 97, 072113 (2010); doi: 10.1063/1.3481372

View online: http://dx.doi.org/10.1063/1.3481372

View Table of Contents: http://scitation.aip.org/content/aip/journal/apl/97/7?ver=pdfcov

Published by the AIP Publishing

\section{Articles you may be interested in}

Stable highly conductive $\mathrm{ZnO}$ via reduction of $\mathrm{Zn}$ vacancies

Appl. Phys. Lett. 101, 102101 (2012); 10.1063/1.4748869

Optical and electrical properties of transparent conducting B-doped $\mathrm{ZnO}$ thin films prepared by various deposition methodsa)

J. Vac. Sci. Technol. A 29, 041504 (2011); 10.1116/1.3591348

Ga-doped $\mathrm{ZnO}$ grown by pulsed laser deposition in $\mathrm{H} 2$ : The roles of $\mathrm{Ga}$ and $\mathrm{H}$

J. Vac. Sci. Technol. A 29, 03 A102 (2011); 10.1116/1.3523296

Effects of ZnO buffer layers on the fabrication of GaN films using pulsed laser deposition

J. Appl. Phys. 101, 093519 (2007); 10.1063/1.2730573

Synthesis and characterization of $\mathrm{ZnO}$ thin film grown by electron beam evaporation

J. Appl. Phys. 99, 123105 (2006); 10.1063/1.2204333

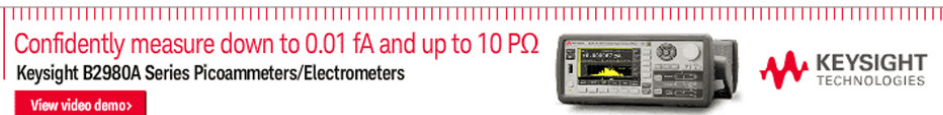




\title{
Highly conductive $\mathrm{ZnO}$ grown by pulsed laser deposition in pure $\mathrm{Ar}$
}

\author{
Robin C. Scott, ${ }^{1}$ Kevin D. Leedy, ${ }^{2}$ Burhan Bayraktaroglu, ${ }^{2}$ David C. Look, ${ }^{3, a)}$ and \\ Yong-Hang Zhang ${ }^{4}$ \\ ${ }^{1}$ School of Mechanical, Aerospace, Chemical and Materials Engineering, Arizona State University, \\ Tempe, Arizona 85287, USA \\ ${ }^{2}$ Air Force Research Laboratory, Wright-Patterson AFB, Ohio 45433, USA \\ ${ }^{3}$ Semiconductor Research Center, Wright State University, Dayton, Ohio 45435, USA \\ ${ }^{4}$ School of Electrical, Computer, and Energy Engineering, Arizona State University, Tempe, \\ Arizona 85287, USA
}

(Received 21 July 2010; accepted 29 July 2010; published online 19 August 2010)

\begin{abstract}
Ga-doped $\mathrm{ZnO}$ was deposited by pulsed laser deposition at $200{ }^{\circ} \mathrm{C}$ on $\mathrm{SiO}_{2} / \mathrm{Si}, \mathrm{Al}_{2} \mathrm{O}_{3}$, or quartz in $10 \mathrm{mTorr}$ of pure Ar. The as-grown, bulk resistivity at $300 \mathrm{~K}$ is $1.8 \times 10^{-4} \Omega \mathrm{cm}$, three-times lower than that of films deposited at $200{ }^{\circ} \mathrm{C}$ in $10 \mathrm{mTorr}$ of $\mathrm{O}_{2}$ followed by an anneal at $400{ }^{\circ} \mathrm{C}$ in forming gas. Furthermore, depth uniformity of the electrical properties is much improved. Mobility analysis shows that this excellent resistivity is mostly due to an increase in donor concentration, rather than a decrease in acceptor concentration. Optical transmittance is approximately $90 \%$ in the visible and near-IR spectral regions. (C) 2010 American Institute of Physics.
\end{abstract}

[doi:10.1063/1.3481372]

Forming-gas (FG) $\left(5 \% \mathrm{H}_{2}\right.$ in $\left.\mathrm{Ar}\right)$ annealing of $\mathrm{ZnO}$ films doped with donor impurities such as $\mathrm{Al}, \mathrm{Ga}$, or In, has been shown to increase conductivity ${ }^{1,2}$ and is often used in preparing transparent conductive oxides (TCOs). The improved conductivity has often been attributed to the ability of $\mathrm{H}$ to directly provide donors and also to passivate negatively charged acceptors, including those causing potential barriers in grain boundaries. ${ }^{3,4}$ However, as shown recently, the bulk electrical properties after FG anneals are not uniform with depth, as evidenced by the thickness dependences of resistivity $\rho$, mobility $\mu$, and carrier concentration $n^{5,6}$ Furthermore, $\mathrm{H}$ is known to be quite mobile, potentially impacting the reliability of certain devices. ${ }^{7}$ Thus, it is preferable to obtain the desired high film conductivity without the assistance of $\mathrm{H}$.

Ga-doped $\mathrm{ZnO}$ films are often grown using pulsed laser deposition (PLD), and generally in an oxygen-rich environment, presumably to ensure stoichiometric films. However, as the partial pressure of oxygen is increased, the film resistivity increases and electron mobility decreases. ${ }^{8,9}$ This high resistivity resulting from excess oxygen is likely related to (1) an increase in compensating point-defect-related acceptors, such as the $\mathrm{Zn}$ vacancy $\mathrm{V}_{\mathrm{Zn}}$ and (2) diffusion of $\mathrm{O}_{2}$ (forming $\mathrm{O}_{2}{ }^{-}$) into grain boundaries (GBs) and other macroscopic defects. The $\mathrm{O}_{2}$ centers at GBs capture electrons that can induce high potential barriers; these barriers can further impede transport by reducing mobility.

In the present work, Ga-doped $\mathrm{ZnO}$ was deposited at $200{ }^{\circ} \mathrm{C}$ in Ar instead of $\mathrm{O}_{2}$. There are reasons to believe that growth in Ar might enhance conductivity by inhibiting the formation of $\mathrm{V}_{\mathrm{Zn}}$ acceptors in the bulk and $\mathrm{O}_{2}$ acceptors at grain boundaries. The Ga-doped $\mathrm{ZnO}$ films were deposited using a Neocera Pulsed Energy deposition tool. The target, consisting a $\mathrm{ZnO}$ ceramic sintered with 3 wt $\% \mathrm{Ga}_{2} \mathrm{O}_{3}$, was ablated with a $248 \mathrm{~nm} \mathrm{KrF}$ pulsed laser operating at a frequency of $30 \mathrm{~Hz}$. The energy density at the target surface was $2.6 \mathrm{~J} / \mathrm{cm}^{2}$. During deposition, the target was rotated at

${ }^{\text {a)} E l e c t r o n i c ~ m a i l: ~ d a v i d . l o o k @ w r i g h t . e d u . ~}$
$40 \mathrm{deg} / \mathrm{s}$ and rastered by $+/-2$ deg to prevent preferential ablation at the center of the target, and the susceptor was rotated at $20 \mathrm{deg} / \mathrm{s}$ The target to wafer distance was fixed at $9.5 \mathrm{~cm}$. The substrate was heated by means of a coiled resistive element located approximately $3 \mathrm{~mm}$ from the substrate wafer. The pressure was controlled for both $\mathrm{O}_{2}$ and Ar processes by flowing the appropriate volume of gas and setting the turbo pump to $250 \mathrm{~Hz}$. The number of laser pulses was chosen to achieve film thicknesses of 30 to $300 \mathrm{~nm}$.

To determine donor $\mathrm{N}_{\mathrm{D}}$ and acceptor $\mathrm{N}_{\mathrm{A}}$ concentrations, temperature-dependent Hall-effect measurements were carried out over a range of 15-320 K using a Lakeshore 7507 apparatus. The values of $\mathrm{n}$ were independent of temperature, and those of $\mu$ and $\rho$, only slightly dependent. It is instructive to compare $\mathrm{n}$ for a sample grown in $\mathrm{Ar}$ (called the " $\mathrm{Ar}$ layer") with that of one grown in $\mathrm{O}_{2}$ (the " $\mathrm{O}_{2}$ layer"). Since the $\mathrm{O}_{2}$ layer had earlier been grown on $\mathrm{SiO}_{2} / \mathrm{Si}$, the Ar layer was also grown on this material; however, up to this point we have noticed no great dependence of $n$ on choice of substrate. The Ar-layer thickness was $82 \mathrm{~nm}$, as measured by spectroscopic ellipsometry (SE), and the $\mathrm{O}_{2}$-layer, $99 \mathrm{~nm}$. In the as-grown $\mathrm{O}_{2}$ layer, $\mathrm{n}$ was low, about $6 \times 10^{19} \mathrm{~cm}^{-3}$. As mentioned earlier, such a low value of $n$ is probably due to high concentrations of $\mathrm{V}_{\mathrm{Zn}}$-related acceptors in the bulk and $\mathrm{O}_{2}$-related acceptors at the GBs. However, when the $\mathrm{O}_{2}$ layer was annealed in $\mathrm{FG}$ at $400{ }^{\circ} \mathrm{C}$ for $10 \mathrm{~min}$, $\mathrm{n}$ increased greatly, up to about $4.3 \times 10^{20} \mathrm{~cm}^{-3}$. This increase is likely due to the $\mathrm{H}$-induced reduction of $\mathrm{O}_{2}$ from the GBs and the $\mathrm{H}$ passivation of $\mathrm{V}_{\mathrm{Zn}}$, i.e., $\mathrm{V}_{\mathrm{Zn}}+2 \mathrm{H} \rightarrow \mathrm{V}_{\mathrm{Zn}}-2 \mathrm{H}$. On the other hand, the Ar layer has a high value of $\mathrm{n}$, as deposited, about $8.1 \times 10^{20} \mathrm{~cm}^{-3}$. Upon annealing in FG, $\mathrm{n}$ actually decreases slightly, while the mobility $\mu$ increases slightly, a scenario that can be explained only by a decrease in the donor concentration $\mathrm{N}_{\mathrm{D}}$. This observation is not in line with conventional wisdom which would have predicted an increase in $\mathrm{N}_{\mathrm{D}}$, due to the addition of $\mathrm{H}$ donors, and a decrease in $\mathrm{N}_{\mathrm{A}}$, due to the passivation of acceptors. Thus, the role of $\mathrm{H}$ is unclear in this case. 


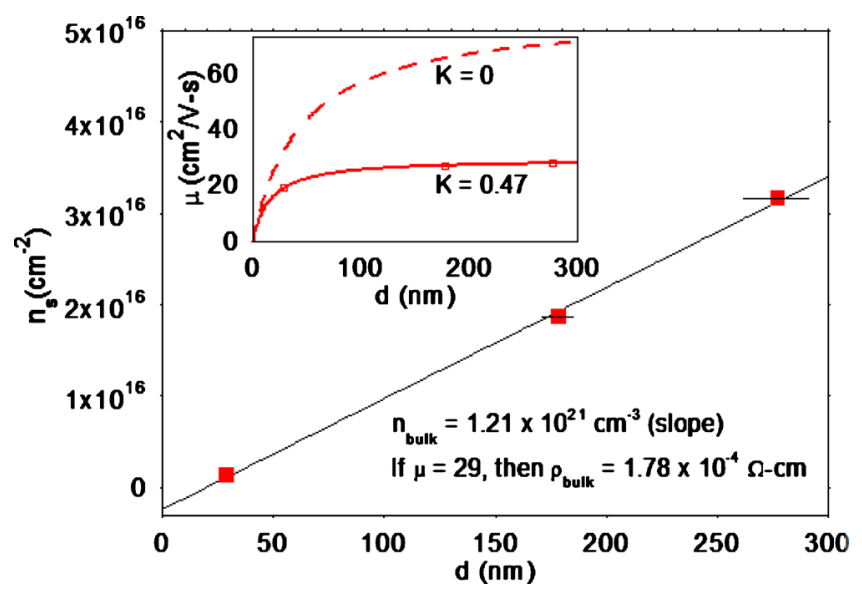

FIG. 1. (Color online) Plots of sheet carrier concentration as a function of layer thickness for samples grown on $\mathrm{Al}_{2} \mathrm{O}_{3}$. Inset: mobility as a function of thickness. The squares are measured data and the solid line is a fit to these data, with $\mathrm{n}=1.2 \times 10^{21} \mathrm{~cm}^{-3}$ and $K=0.47$. The dashed line is the hypothetical mobility for $\mathrm{n}=1.2 \times 10^{21} \mathrm{~cm}^{-3}$ and $K=0$, or equivalently, $\mathrm{N}_{\mathrm{A}} \ll \mathrm{N}_{\mathrm{D}}$.

Thicknesses of Ga-doped $\mathrm{ZnO} / \mathrm{SiO}_{2} / \mathrm{Si}$ films deposited in oxygen are routinely measured using SE with a wellestablished model for the layer stack. However, as the optical constants of Ga-doped $\mathrm{ZnO}$ films deposited in Ar have not been fully characterized, the films were deposited on $\mathrm{Al}_{2} \mathrm{O}_{3}$ to assure correct thicknesses for $\rho$ and n calculations. An abrupt step was obtained for profilometer (Tencor P-10) measurements by partially masking the Ga-doped $\mathrm{ZnO}$ film, then immersing the wafer into an acid solution known to have a high selectivity for $\mathrm{ZnO} /$ sapphire, (1:1000 HCL:deionized water). In Fig. 1, sheet carrier concentration $\mathrm{n}_{\mathrm{s}}$ versus thickness $d$ is plotted with error bars indicated for the two thickest samples. The data were taken at room temperature but there is very little change in $\mathrm{n}$ from $15-320 \mathrm{~K}$. Within error, the points fall on a straight line, and the slope of this line is just the volume carrier concentration $\mathrm{n}=1.2 \times 10^{21} \mathrm{~cm}^{-3}$. (More points will be needed to determine if there is a slight nonlinearity in the data.) The $y$-axis intercept, $-2 \times 10^{15} \mathrm{~cm}^{-2}$, can perhaps be interpreted as a depletion charge due to acceptors in the $\mathrm{ZnO} / \mathrm{Al}_{2} \mathrm{O}_{3}$ interface region; however, again more points will be necessary to provide a definite conclusion in this matter.

The room-temperature mobilities of the three points are plotted as a function of thickness in the inset of Fig. 1. For samples such as these, the low-temperature mobilities are only slightly higher than those at room temperature. This is because most of the scattering is due to the ionized donors and acceptors, rather than phonons, even at room temperature. To fit the mobility data we apply a recently developed model that includes degenerate Brooks-Herring theory along with an empirical formula for boundary scattering, as follows: ${ }^{5}$

$$
\mu(d, n, K, C)=\left[\mu_{i i}(n, K)^{-1}+\mu_{b d r y}(d, n, C)^{-1}\right]^{-1},
$$

where

$$
\mu_{b d r y}(d, n, C)=\frac{e}{\hbar} \frac{d / C}{\left(3 \pi^{2} n\right)^{1 / 3}}=\frac{10.58}{C} \frac{d_{\mathrm{nm}}}{n_{20}^{1 / 3}}\left(\frac{\mathrm{cm}^{2}}{\mathrm{~V} \mathrm{~s}}\right),
$$

$$
\begin{aligned}
\mu_{i i}(n, K) & =\frac{24 \pi^{3} \varepsilon_{0}^{2} \hbar^{3}}{Z^{2} e^{3} m^{* 2}} \frac{n}{N_{i i}} \frac{1}{\ln [1+y(n)]-\frac{y(n)}{1+y(n)}} \\
& =\frac{146.9}{\ln \left(1+6.46 n_{20}^{1 / 3}\right)-\frac{6.46 n_{20}^{1 / 3}}{1+6.46 n_{20}^{1 / 3}}} \frac{1-K}{1+K}\left(\frac{\mathrm{cm}^{2}}{\mathrm{~V} \mathrm{~s}}\right) .
\end{aligned}
$$

Here, $d_{n m}$ is the layer thickness in units of $n m, n_{20}$ is the carrier concentration in units of $10^{20} \mathrm{~cm}^{-3}$, and $C$ is an empirical constant which depends on the details of surface and interface scattering. For the samples discussed in Ref. 5, a value of $\mathrm{C}=4$ best fits the data, while for the three points presented in Fig. 1, $\mathrm{C}=2.5$ gives a good fit. The other fitting parameter is $K=0.47$, and since $K=\mathrm{N}_{\mathrm{A}} / \mathrm{N}_{\mathrm{D}}$ and $n=\mathrm{N}_{\mathrm{D}}-\mathrm{N}_{\mathrm{A}}$, we get finally, $\mathrm{N}_{\mathrm{D}}=2.3 \times 10^{21} \mathrm{~cm}^{-3}$ and $\mathrm{N}_{\mathrm{A}}=1.1$ $\times 10^{21} \mathrm{~cm}^{-3}$. These numbers must be considered tentative but clearly the layer has a very high donor concentration, composed mostly of Ga. Unfortunately, the layer also has a high acceptor concentration, and a key goal of TCO development is to get rid of the acceptors. Note that if $\mathrm{n}$ were the same but $\mathrm{N}_{\mathrm{A}} \ll \mathrm{N}_{\mathrm{D}}$ (i.e., $K \sim 0$ ), then $\mu$ versus $d$ would follow the dashed line in the inset of Fig. 1, and the resistivity for thick samples would drop by about a factor three at room temperature. For very thin samples, of course, surface/ interface scattering, and ultimately quantum effects, will always limit the mobility.

Unalloyed Ohmic contacts were fabricated using e-beam evaporated $\mathrm{Ti} / \mathrm{Pt} / \mathrm{Au}: 20 / 30 / 350 \mathrm{~nm}$ at room temperature. Excellent specific contact resistance values of 2-4 $\times 10^{-8} \Omega \mathrm{cm}^{2}$ were measured using the transmission line method (TLM). Temperature stress tests were applied to samples in air at temperatures up to $350{ }^{\circ} \mathrm{C}$ by keeping samples at each temperature step for $1 \mathrm{~h}$. No significant change in contact resistivity was observed in this temperature range. At higher temperatures, alloyed contacts were formed and the contact resistance dropped sharply. The bulk resistivity also was not strongly affected by the stress tests, increasing from $5 \times 10^{-4}$ to $7 \times 10^{-4} \Omega \mathrm{cm}$, indicating that both the conductivity of the films and the unalloyed Ohmic contacts are stable with temperature.

For transparent electrode applications, the most important parameters are the sheet resistance $\rho_{\mathrm{s}}$ and the optical transmittance OT. For the $277 \mathrm{~nm}$ sample in Fig. 1, $\rho_{\mathrm{s}}$ $=7.1 \Omega / \mathrm{sq}$, a very impressive value. Unfortunately, the backsides of our $\mathrm{Al}_{2} \mathrm{O}_{3}$ wafers were not polished, so it was necessary to measure OT on other layers, grown on polished quartz. In Fig. 2, the wavelength dependence of the transmittance, measured with a Varian Cary 5000 spectrophotometer, is shown for $\mathrm{Ar}$ and $\mathrm{O}_{2}$ layers grown on quartz under conditions nearly identical to those pertaining to the samples of Fig. 1. We note that the OT for as-deposited $\mathrm{O}_{2}$ layers (not shown) is nearly $90 \%$ from the band edge all the way to $2500 \mathrm{~nm}$ but unfortunately the conductivity of such layers is too low for TCO applications. For the highly conductive layers, i.e., the $\mathrm{O}_{2}$ layers annealed in $\mathrm{FG}$, and the as-grown $\mathrm{Ar}$ layers, the transmission above $1000 \mathrm{~nm}$ decreases due to free-carrier absorption, as expected. The decrease in this region is higher for the Ar layer because its carrier concentration is higher; however, in the visible region, the Ar layer has 


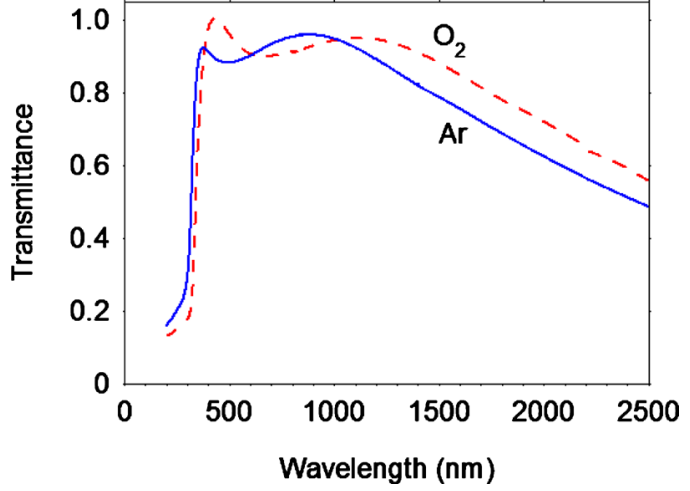

FIG. 2. (Color online) Optical transmittance as a function of wavelength for Ga-doped $\mathrm{ZnO}$ deposited at $200{ }^{\circ} \mathrm{C}$ and 10 mTorr in Ar (solid line) and $\mathrm{O}_{2}$ (dashed line).

In conclusion, highly conductive Ga-doped $\mathrm{ZnO}$ with excellent optical transparency has been achieved at low deposition temperatures using PLD in a pure Ar environment without the need for postdeposition anneals. The significant increase in conductivity is attributed mainly to improved $\mathrm{Ga}$ incorporation on donor sites, although a detailed model of growth dynamics has yet to be worked out. Sheet resistance versus thickness data suggest that the bulk carrier uniformity in thick films grown in $\mathrm{Ar}$ is much better than that for thick films grown in $\mathrm{O}_{2}$ and then annealed in FG.
This work was carried out at the Air Force Research Laboratory, Wright-Patterson AFB, Dayton, OH. We wish to thank T. A. Cooper for the Hall-effect measurements. The work of R.C.S. and Y.H.Z. was partially supported by Science Foundation Arizona, Contract Nos. SRG 0190-07 and SRG 0339-08, and by the Air Force Research Laboratory/ Space Vehicles Directorate, Contract No. FA9453-08-20228. The work of D.C.L. was partially supported by AFOSR under Grant No. FA9550-10-1-0079 (K. Reinhardt) and NSF under Grant No. DMR0803276 (L. Hess).

${ }^{1}$ B. Du Ahn, S. H. Oh, C. H. Lee, G. H. Kim, H. J. Kim, and S. Y. Lee, J. Cryst. Growth 309, 128 (2007)

${ }^{2}$ K. Yim, H. W. Kim, and C. Lee, Mater. Sci. Technol. 23, 108 (2007).

${ }^{3}$ E. Millon, J. Perriere, S. Tircot, and C. Boulmer-Leborgne, Proc. SPIE 7005, 70051A (2008).

${ }^{4}$ B. G. Choi, I. H. Kim, D. H. Kim, K. S. Lee, T. S. Lee, B. Cheong, Y.-J. Baik, and W. M. Kim, J. Eur. Ceram. Soc. 25, 2161 (2005).

${ }^{5}$ D. C. Look, K. D. Leedy, D. H. Tomich, and B. Bayraktaroglu, Appl. Phys. Lett. 96, 062102 (2010).

${ }^{6}$ D. C. Look, K. Ghosh, and K. D. Leedy, Zinc Oxide and Related Materials-2009, MRS Symposia Proceedings No. 1201 (Materials Research Society, Pittsburgh, 2010), p. 35.

${ }^{7}$ B. Bayraktaroglu, K. Leedy, and R. Bedford, Appl. Phys. Lett. 93, 022104 (2008).

${ }^{8}$ H. Qi, Q. Li, C. Wang, L. Zhang, and L. Lv, Vacuum 81, 943 (2007).

${ }^{9}$ S.-M. Park, T. Ikegami, and K. Ebihara, Jpn. J. Appl. Phys., Part 1 44, 8027 (2005) 